\title{
CrimRxiv
}

\section{Review 2 of "Policing}

Perspectives Concerning

Confusion and Uncertainty

in Policing Practices with

'Honour'-Based Crimes and

Forced Marriages"

Natasha Mulvihill

Published on: Feb 16, 2021

DOI: 10.21428/cb6ab371.e3169b56

License: Creative Commons Attribution 4.0 International License (CC-BY 4.0). 
Vote: Publish pending minor changes

[For votes to count, referees must reasonably explain why they voted as they did. Thus, please explain your vote. If you voted to publish pending minor changes, specify each change, why it is needed, and, possibly, how it should/could be done.]

p. 3 - Consider whether research question 2 and 3 should be swapped in order. How police define and distinguish $\mathrm{HBC}$ on the job feels as it should come before how they intervene to prevent and protect.

p.11 -I fully concur with your comments about the 'honour' discourse being problematic, divisive and consonant with political agenda around race, immigration, Othering etc. I agree that the continuities and connections between experiences of women globally are often missed, as some seek to say 'those groups over there are patriarchal' and yet fail to identify 'their own' group's patriarchal practices.

At the same time, and aside from the terminology, my work in this area suggests that women (and men) are nevertheless experiencing something (which we'll call HBC for a moment) which is both similar to and qualitatively different from DVA or FV. But it is not culture which defines it so much as the way it is exercised. It is the compounding layers of coercion through different relationships and networks within that individual's life.

And so, if only to recognize the particular strictures facing those experiencing this form of gender violence, it seems important ensure police are cognizant of these aspects, in order to inform their practice. They need to understand the tools of perpetration and its impact but, as you say, understand that they are part of the wider panoply of gender violence, which affects all communities.

p.13 and p.14 You cite a particular educator - Aruna Papp - who is critiqued strongly by your participant(s). Personally, I would say put [training provider] or [HBC educator] or similar - I would not actually name someone.

p.15 - Similarly, you mention Farah Khan and Deepa Mattoo.

In your discussion on Aruna Papp, there is something about 'survivor-led' training, I think. Such work can be valuable and powerful. However, as you imply, survivor-trainers can come to personify an issue. Good trainers will be cautious not to generalize their own experience to everybody's experience. You might include something about this, rather than refer to people personally?

Overall, this is a very interesting paper. You have justified the gap around understanding Canadian police perceptions of 'honour'-based crimes. Your data is insightful and your analysis deftly handled. I like your practical suggestions at the end. 
Thank you for the opportunity to read your work. 